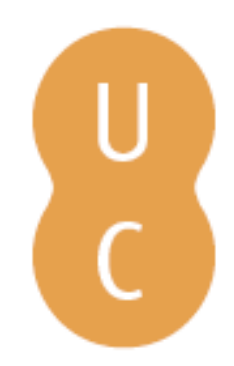

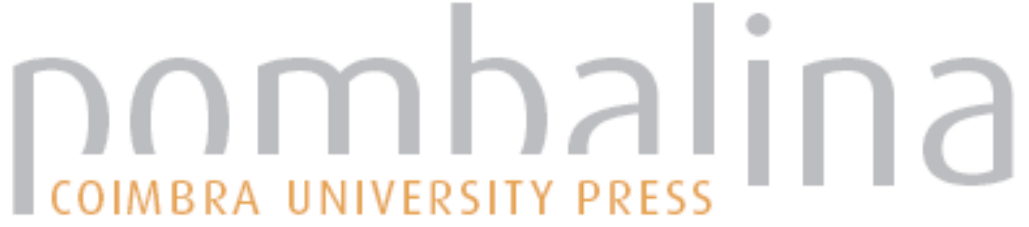

\section{Débito de Almeida Garrett a Plutarco}

Autor(es): $\quad$ Ferreira, José Ribeiro

Publicado por: Imprensa da Universidade de Coimbra

URL

persistente:

URI:http://hdl.handle.net/10316.2/30749

DOI:

DOI:http://dx.doi.org/10.14195/978-989-8281-94-4_4

Accessed : $\quad$ 26-Apr-2023 16:00:30

A navegação consulta e descarregamento dos títulos inseridos nas Bibliotecas Digitais UC Digitalis, UC Pombalina e UC Impactum, pressupõem a aceitação plena e sem reservas dos Termos e Condições de Uso destas Bibliotecas Digitais, disponíveis em https://digitalis.uc.pt/pt-pt/termos.

Conforme exposto nos referidos Termos e Condições de Uso, o descarregamento de títulos de acesso restrito requer uma licença válida de autorização devendo o utilizador aceder ao(s) documento(s) a partir de um endereço de IP da instituição detentora da supramencionada licença.

Ao utilizador é apenas permitido o descarregamento para uso pessoal, pelo que o emprego do(s) título(s) descarregado(s) para outro fim, designadamente comercial, carece de autorização do respetivo autor ou editor da obra.

Na medida em que todas as obras da UC Digitalis se encontram protegidas pelo Código do Direito de Autor e Direitos Conexos e demais legislação aplicável, toda a cópia, parcial ou total, deste documento, nos casos em que é legalmente admitida, deverá conter ou fazer-se acompanhar por este aviso. 


\section{Joaquim Pinheiro José Ribeiro Ferreira Nair Castro Soares Rita Marnoto}

\section{Caminhos de Plutarco na EUROPA}

$2^{a}$ EDIÇÃo REVISTA E AUMENTADA 


\section{Débito de Almeida Garrett a Plutarco}

José Ribeiro Ferreira (Universidade de Coimbra)

Por várias vezes o próprio Garrett se declara devedor de Plutarco ou o erige como seu paradigma. Além de nomear e apresentar como modelos muitos dos biografados das Vidas do polígrafo de Queroneia, sem dizer explicitamente que essa é a sua fonte, confessa abertamente em outros passos que está a imitar Plutarco ou sugere que ele seja o modelo a seguir. Tal torna-se evidente em especial no opúsculo Da Educação. A comunicação procura analisar esse débito, confessado, ao autor de Queroneia, com mais demora no referido opúsculo.

Introdutor do Romantismo em Portugal, Almeida Garrett distinguiu-se como romancista, como poeta, como dramaturgo, como teorizador, como parlamentar. Com consistente formação clássica e bom conhecedor da história e da cultura da Grécia e de Roma antigas, mesmo depois de, na abertura da Dona Branca (1848) - cuja publicação coincide com a data de saída da primeira obra romântica - ter abjurado os «Áureos numes de Ascreu, ficçóes risonhas / Da culta Grécia amável», continuou a conviver com os clássicos. E Plutarco é um dos autores greco-romanos mais citados e mais recorrentes, talvez apenas superado por Homero, Virgílio, Horácio e Aristóteles.

Almeida Garrett foi um homem comprometido com a Revolução Liberal de 1820, um homem que, 
a favor da liberdade, luta contra a tirania. Daí que considere (1963: 739) que Plutarco deve ser lido, referindo-o explicitamente cerca de 20 vezes; daí que alguns dos retratados nas suas Vidas, lendários ou históricos, sejam nomeados, sobretudo na obra política e parlamentar. São da especial predilecção de Garrett Catão de Útica, Epaminondas, Temístocles, Aristides, Sócrates, Alcibíades, Fabrício, Bruto, ${ }^{1}$ Licurgo, os Gracos, Horácio Colces, Fábio, Cipião, Sertório, Coriolano ou Tito.

Cito apenas alguns passos dos muitos que nos dão essa visão paradigmática de figuras de Plutarco. Começo por uma citação retirada de um texto incluído em Política, em que Garrett - escrevendo em 1832, decorridos cinco anos de perseguiçóes dos absolutistas aos liberais, com prisóes e desterros, e desaparecidos muitos democratas de 1820 - refere restarem, apesar disso, alguns desses democratas que equipara a Aristides, a Catão, a Bruto (1963: I 1229):

(....) já bem pouco atidos às reminiscências das escolas, continuaram a ser Aristides, Catôes, e Brutos e nem sequer se lembraram de que sobre as cinzas desses varóes ilustres, cujas ideias eram inegavelmente progressivas na época em que eles viveram, pesavam já mais de dois mil anos. ${ }^{2}$

${ }^{1}$ Tanto pode ser Lúcio Júnio Bruto, a cujo exemplo recorre mais abaixo, como Marco Bruto, que os dois nomeia Garrett.

${ }^{2} \mathrm{O}$ passo é tirado dos "Estatutos da Sociedade Conservadora do Sistema Monárquico representativo em Portugal”, datados de 8 de Julho de 1841. 
Aristides, Catão, Bruto são todos heróis de Plutarco, como o são também os que aparecem citados em texto de género totalmente diverso, $O$ Retrato de Vénus, em que fala do descaminho que levam as artes (1963 II: 648):

Sem rumo as artes desgrenhadas fogem,

A Roma de Catão, de Augusto a Roma

Não é de Pio a efeminada corte;

E em vez de um Fábio tardador, de um Quíncio,

De um Bruto, um Mânlio; prostituta prole

No desonrado Capitólio avulta.

Catão, Fábio, Bruto, Mânlio são de novo figuras de Plutarco. Apenas mais uma citação, retirada dos Discursos Parlamentares - do que proferiu na Câmara de Deputados, na sessão de 8 de Fevereiro de 1840 (1963: II 1287 sqq.) - na qual voltam a surgir figuras das biografias de Plutarco. Reagindo à acusação de colaboracionismo feita na Câmara ao seu partido, Garrett verbera os que se aproveitam do regime e dos cargos para enriquecerem e afidalgarem e vêm acusar de 'bastardos' quem coopera - palavra que está na origem da acusação - com a monarquia; que adulam o povo na Câmara eà noite se sentam à mesa dos ricos, mas criticam os que, tendo-se denodadamente esforçado pela pátria e lutado pela liberdade, apontando sempre os erros e as deficiências, falam de colaborar e de "ordem que é razão e justiça»; a esses hipócritas críticos, compara-os Garrett ironicamente e por contraposição a figuras de Plutarco, 
devolvendo-lhes o epíteto de 'bastardos' e apelidando-os de «Gracos ridículos, de «Publícolas palhaços que ora se enfeitam da coroa cívica nos Comícios, ora das pérolas de barão feudal nos palácios», que, através da lisonja e da mentira, pretendem ter ao mesmo tempo «as honras de Catão e o poder de César», que sempre conseguem estar do lado do poder, já que é doce invocar o nome Jesus Cristo para lhe tosquiar o rebanho, em vez de o apascentar, e invocar o nome do Rei "para reinar mais que ele»; é doce dominar o povo pela lisonja e «dispor da força bruta» (1963: II 1296-1297):

(....) era mais doce ainda, mais suave que tudo, dominar as turbas com a lisonja; dispor da força bruta, que tanto mais serva e escrava é quanto mais cuida mandar; concentrar em si todos os direitos, monopolizar toda a liberdade para si só; - ter as honras de Catão e o poder de César; almoçar no foro os rábanos de Fabrício, e banquetear-se à noite nos temulentos palácios de Lúculo.

E a emprazadora da Ordem e os importunos dos Doutrinários a patentear ao Povo estes mistérios Eleusinos, a abrir diante dos seus olhos as austeras, as desenganadoras páginas da História, a mostrar-lhes aí como dos Gracos se fazem Catilinas, e dos Mários ditadores, como o tribuno se converte sempre em áulico, o publícola em palaciano, mal as turbas se fatigam de seu reinado nominal, e o Poder, por sua natural tendência, ou se concentra no feixe consular, ou na vara ditatória, ou no diadema imperial, ou no simples bastão do protectorato - em qualquer símbolo da Realeza que se destruiu mentindo, que mentindo se restabelece. 
Estendi um pouco a citação, porque ela permite, além de mostrar como Almeida Garrett recorre com mão assídua aos biografados de Plutarco, sobretudo a alguns deles - e nesta citação estão presentes os Gracos, Publícola, Catão, César, Fabrício, Luculo, Mário -, evidencia ainda quanto a cultura clássica está nele entranhada e com facilidade e naturalmente aparece na argumentação.

Catão de Útica é um desses heróis plutarqueanos apontados como paradigma, é inclusive o mais citado na obra de Garrett. Tomado sempre como símbolo da luta pela liberdade e contra a tirania, a esse nobre romano dedicou a tragédia Catão, em cinco actos. Elegendo como assunto os últimos momentos de vida do protagonista, que se identificam com a resistência das forças republicanas em Útica ao domínio de César, a peça culmina com o suicídio de Catão. São objectivos desta tragédia a exortação ao amor da liberdade e, ao mesmo tempo, incitação ao espírito de moderação e de respeito da lei. Já em outro trabalho mostrei o débito a Plutarco desta tragédia de Garrett, pelo que me limito agora a remeter para esse estudo e a sublinhar alguns aspectos. ${ }^{3}$ A vitória de César sobre Pompeu deixa em situação delicada os defensores da Roma livre que, agrupados em Útica em volta de Catão, se consideram o verdadeiro senado romano e decidem resistir aos desejos de César. Mas nem todas as figuras da peça - que, através dos diálogos e monólogos, se apresentam, manifestam e

${ }^{3}$ Vide F. C. Bordoy 2001: 291-304. 
descobrem os seus propósitos - têm lídimas intenções e, entre elas, há focos de traição: Catão, o homem estóico, honrado, impoluto, defensor acérrimo da liberdade que prefere a morte a submeter-se à tirania de César, pelo que se suicida no final, no Acto $\mathrm{V}$, consumada a derrota e ocupada Útica; Marco Bruto, jovem exaltado e sempre pronto a enfrentar César, ansioso mesmo em derramar o sangue do tirano, que na cena final Acto $\mathrm{V}$ e final da tragédia promete vingar-se matando o ditador, mesmo depois de saber que é seu filho; Mânlio, um homem moderado, conciliador e sensato que, por essa razáo, foi indevidamente tomado como o cavalo de Tróia das forças republicanas; Semprónio, um demagogo adulador da plebe que, por inveja e ódio a Catão, não só se coloca ao lado de César, procurando escancarar as portas de Útica ao exército do ditador, como tenta ainda aliciar algumas das parcas forças de defesa desse grupo de resistentes, como acontece no Acto III, de maneira fraudulenta, com o jovem rei da Númida, Juba, que tem por Catão uma adoração de filho e o apoia com o seu exército; o filho de Catáo, Pórcio, que admira o pai e acaba por encontrar a morte em consequência da traição de Semprónio; Décio, enviado de César e amigo de Bruto; e o Povo, sobretudo presente no último Acto pelo seu desespero, mas também pela confiança e estima por Catão.

Da leitura da tragédia, ressalta que a sua acção se baseia em grande medida na parte final do Cato Minor de Plutarco, débito que aliás o próprio Almeida Garrett confessa - bem como a Tito Lívio 
- nestas significativas palavras do "Prefácio da segunda edição" (1963 II: 1614):

O desanimador estudo do coraçáo humano, o fatal conhecimento das humanas paixóes, e de sua influência e acção nas revoluçóes políticas, o habilitaram para entender agora melhor o seu Tito Lívio e o seu Plutarco. Assim comentados pela experiência de dez anos de revoluçáo, estes dois grandes fanais da história antiga guiaram o autor da tragédia nas reformas que nela fez, no desenho de seus caracteres, e no colorido de muitas cenas...

E em estoutras da "Carta a um amigo", publicada na primeira edição, em que - justificando-se da acusação de ter imitado o Catão de Addison, publicado uns anos antes - Almeida Garrett, embora reconhecendo possuir o seu Catão «expressóes, versos inteiros imitados de Addison» (raros todavia), sublinha as diferenças entre as duas obras e considera que «a semelhança decerto mais a produziu a comum leitura de Plutarco do que nenhuma outra coisa» (1963: II 1615) e que trabalhou com base nas Vidas de Catão de Útica e de César (1963: II 1618):

Posso dizer que trabalhei conscienciosamente e com escrúpulo no aperfeiçoar deste drama, procurando sobretudo dar-lhe aquele sabor antigo romano que até já nos derradeiros escritores latinos estava perdido.... Para esse fim somente, para me familiarizar e pôr, como se fora de casa, com os meus autores, traduzi de Plutarco as vidas de Catão (o menor ou uticense) e de César. Pesa-me que os limites circunscritos do volume me não deixem inserir aqui 
ao menos a primeira. Julgar-se-ia melhor da sinceridade e boa fé com que procurei transfundir, em suco e sangue para a verdade dramática, a verdade e exacção histórica de que aqueloutra vive, isto é, a dos costumes e caracteres.

Quero ainda referir que, se o débito da tragédia Catão a Plutarco reside em especial na ambiência que Almeida Garrett transmitiu à sua peça e no modo como trabalhou as personagens, são também muitos os passos que apresentam significativas identidades com outros tantos trechos das Vidas de Plutarco. É o próprio autor a indicar, nas notas que pospóe à tragédia (1963: II 1745-1761), as fontes do seu Catão e os paralelismos existentes entre essa tragédia e a obra do biógrafo de Queroneia - ao todo enumera 22 passos que foram beber às suas Vidas Paralelas, remetendo para diversas delas.

Se, como vimos, as figuras de Plutarco são com assiduidade nomeadas e se na tragédia Catão a influência é clara, o filósofo de Queroneia está subjacente em outras obras e passos de Garrett que, neles, ora confessa o débito, ora declara que o imita e deve ser imitado, ora o refere. A presença e paradigma de Plutarco é sobretudo com insistência apontado no opúsculo $D a$ Educação, com cuja análise terminaremos estas observaçóes. Antes porém gostaria de abordar três outras ocorrências do nome do escritor de Queroneia, uma no discurso fúnebre em memória de D. Helena Feio de Sousa e Meneses Aranha (Janeiro de 1869), 
outra na "Carta de guia para eleitores" e a terceira num dos Discursos Parlamentares (respectivamente, 1963: I 1030, 1083 e 1267), todas elas e exaltarem Plutarco ou as suas figuras como modelo.

$\mathrm{Na}$ primeira das três referidas ocorrências, um discurso fúnebre em memória de uma jovem de dezanove anos, D. Helena Feio de Sousa e Meneses Aranha, ao exaltar a importância do recolhimento feminino, apresenta como paradigma a figura de uma matrona romana, possivelmente Cláudia, que equipara aos mais emblemáticos dos biografados de Plutarco (1963: I 1030):

Aquela matrona romana que ficou tão imortal como os maiores homens de Plutarco - no seu memorável epitáfio, o que se dizia dela? Que esteve em casa e que fiou na roca.

Embora sem a nomear, Garrett tem com certeza em mente a figura de Cláudia que apenas considera digno de ser especificado no seu epitáfio - além da sua fala aprazível e do seu gracioso andar, de amar o marido e criar os filhos - o cuidar da sua casa e o fiar a lã (Bücheler, C.E. 52). É bem possível que não esteja também de todo ausente a imagem de Lucrécia, descrita num conhecido passo de Tito Lívio 1. 57-60 que a apresenta a trabalhar a lã com as criadas, enquanto o marido combatia, e que, violentada pelo rei Sexto Tarquínio, se suicida, fazendo jurar ao pai, ao marido e a Lúcio Júnio Bruto que «o adúltero não ficará impune», juramento que está na origem da declaração 
do último de que não consentirá que nem os Tarquínios nem outra qualquer pessoa reinem em Roma, ponto de partida para a queda da monarquia. Tenha-se em conta que Lúcio Júnio Bruto - explicitamente apontado como exemplo no Da Educação, como veremos mais adiante - é um dos mais citados por Garrett e a luta contra a tirania e o despotismo uma das suas constantes.

Interessa sobretudo ao meu objectivo sublinhar que são os heróis das Vidas de Plutarco os paradigmas máximos a que Garrett equipara essa mulher romana ou seja, para utilizar as suas palavras acima citadas, «ficou tão imortal como os maiores homens de Plutarco».

No segundo passo, da "Carta de guia para eleitores" (1963: I 1073 sqq.), voltam a aparecer os'homens de Plutarco' - designação que genericamente Garrett lhes dá - como modelo maior. A determinada altura fala dos juízes e da independência que devem ter em relação ao poder político (1963: I 1083):

(....) para julgar é necessário que haja homens inteiramente isentos da influência ministerial, que não conheçam senão a lei, que não temam senão a ela, alheios a todas as paixóes, estranhos a todos os interesses. Enquanto estas duas estiverem cumuladas, façam os melhoramentos que quiserem, decretem as próprias leis de Platão, ponham em seus lugares todos os homens de Plutarco, nada fazem, nada reformam, nada melhoram e nada conseguem.

Esta soberania da lei e da justiça, que era um dos ideais gregos e também romanos, sublinhado em várias das figuras de Plutarco, é aqui exaltada e aplicada ao 
estado moderno e liberal. A mesma valoração da lei se encontra num passo de uma intervenção dos Discursos Parlamentares, proferida na sessão de 9 de Outubro de 1837, em que Garrett procura mostrar as vantagens e inconvenientes da nomeação régia ou da eleição popular, no que respeita à constituição da Câmara ou Conselho Revisor das leis aprovadas - uma espécie de Tribunal Constitucional de então. Garrett rejeita a Câmara ou Senado constituído por escolha do rei e prefere-lhe a eleição. $\mathrm{O}$ texto que a seguir se cita insere-se nos argumentos em que apoia essa rejeição da escolha pelo rei e fala das facçóes que então tudo dominavam (1963: I 1267):

Quem se atreverá a colocar nas máos destes seis eleitores privilegiados os destinos e esperanças da naçâo? Quando todos fossem táo virtuosos como seis homens de Plutarco, quando nestes seis portentos de sabedoria e integridade se refundissem os sete sábios da Grécia, como haviam eles, nos tempos calamitosos em que vivemos, evadir-se à influência omnipotente de qualquer facção que domine?

A presença de Plutarco é em especial significativa no opúsculo Da Educaçâo, um tratado pedagógico constituído por um conjunto de doze cartas endereçadas à rainha $\mathrm{D}$. Maria, nas quais procura sugerir a feitura de um manual educativo que, existente em outros países, Portugal ainda não possuía. Seria adaptado às diversas idades e sexos, começando na meninice - ou puerícia, para usar o termo de Garrett - até à idade adulta ou virilidade. 
Ao longo da exposição do opúsculo Garrett apresenta Plutarco algumas vezes como paradigma, embora declare na "Carta primeira" (1963 I: 687) - ao teorizar e apresentar o plano geral do livro e ao falar da autoridade das citaçóes e dos escritores - não «pretender examinar, um por um, os sistemas e os tratados de Aristóteles e Plutarco, de Fénelon e Rollin, de Rousseau e Helvécio, de Loke e Condillac, de Genlis e de tantos outros enfim antigos e modernos que da matéria trataram». Esta afirmação de Garrett poderia sugerir que teria em mente o De liberis Educandis - e não temos a certeza de que náo fosse esse o caso, já que traduzido para latim em Florença, em 1410, por Guarino Veronense (tradução publicada em 1471), esse tratado atribuído a Plutarco exerceu forte influência desde o Renascimento, com sucessivas traduçóes a aparecerem, quer em latim, quer nas línguas nacionais, e com diversos tratados de educação que o tomam como modelo. ${ }^{4}$

As referências posteriores, contudo, mostram que assim não acontece: são sobretudo as Vidas Paralelas que estão subjacentes e não o De Liberis Educandis. Assim, na "Carta Sexta" (1963: I 729740) propóe uma educação que - além de vários escritores modernos - tenha por base Fedro, Esopo, Plutarco, Valério Máximo e que estabeleça paradigmas de figuras históricas. A carta aborda a educação no

${ }^{4}$ Desde D.I Wittenbach 1820: 1-30 que este opúsculo tem sob suspeita a autoria e é considerado apócrifo. Para a influência e diversas traduçôes que o tratado teve em latim a nas línguas nacionais vide J. Sirinelli 1987: 3-6. 
final do segundo período etário, ou seja da passagem da puerícia à adolescência, considera a história como complemento moral dessa educaçáo, reflecte sobre o primeiro livro que se deve dar às crianças e prefere um que contenha paradigmas históricos gregos, romanos, de outros povos, mas sobretudo portugueses. É neste contexto de aconselhamento a escolher exemplos da história de Portugal que Plutarco volta a ser nomeado. Assim em determinado passo da carta (1963 I: 734) refere que as "grandes acçóes de virtude», os "feitos de valor e heroísmo de todo o género» - e também os "crimes e vícios e faltas - que os Portugueses praticaram ou cometeram desde a extremidade da Europa à África, à América e até aos confins da Ásia, dariam «matéria para muitos volumes de Valérios Máximos, Cornélios Nepotes e Plutarcos».

$\mathrm{Na}$ apresentação ou escolha dos exemplos, Garrett é explícito em declarar, em vários passos da carta, o seu débito a Plutarco. Apresento alguns deles. Depois de se referir à utilização das fábulas na educação - dissertando sobre o sentido etimológico do termo ${ }^{5}$ e citando Esopo, Fedro, La Fontaine - e de lhes apontar alguns inconvenientes, aconselha, de preferência, um livro com paradigmas históricos, à maneira do que fizeram Plutarco e Valério Máximo (1963: I 731):

${ }^{5}$ Escreve a tal propósito em 1963 I: 731: «Demais, fábula quer dizer fingimento; e fingimento é mentira; e mentira nem zombando se deve ensinar às crianças: é como brincos de lume, que a mais descuidada ama-seca lhes não permite». 
Um bom livro que contivesse - primeiro, histórias verdadeiras, bem escolhidas e tiradas das antigas e modernas crónicas, - segundo, vidas de homens célebres, uma espécie de Valério Máximo e Plutarco da mocidade, em que se achassem, não Gregos e Romanos somente, mas varóes ilustres de todos os povos, e principalmente nossos, - um livro tal preencheria todas as condiçóes que em vão se buscam nas fábulas. Epaminondas, Aristides, Sócrates, Alcibíades, Aníbal, Mitridates, Bruto, Fabrício, Catão, Tito - o próprio Nero - Atila, Teodorico, Rodrigo, Belisário, Alfredo, Henrique IV, Afonso-Sábio, Afonso Henriques, Egas Moniz, Nun'Álvares, Las Casas, Bartolomeu dos Mártires, Martim de Freitas, João de Castro, Albuquerque, Pacheco, o Infante Santo, Howard, Turenne, Fénelon, e mil outros de todos os tempos e naçóes, ensinarão, pelo menos, táo boa moral como a "comadre cegonha, o compadre rato" e outras distintas personagens das crónicas de Esopo e seus discípulos.

As reservas de Garrett em relação à fábula aparecem justificadas (1963: I 731) com o facto de tal termo querer «dizer fingimento; e fingimento é mentira; e mentira nem zombando se deve ensinar às crianças». Daí a sua preferência pelas personalidades históricas, em que as greco-romanas aparecem em plano de evidência. Às nomeadas a par de heróis de outras épocas e países, no passo citado, a carta acrescenta outras ao longo da exposição, a ponto de nos dar uma longa lista, na maioria, de figuras que aparecem em Plutarco: Epaminondas, Aristides, Sócrates, Alcibíades, Fabrício, Catão, Bruto, ${ }^{6}$

${ }^{6}$ Tanto pode ser Lúcio Júnio Bruto, a cujo exemplo recorre 
Licurgo, os Gracos, Horácio Cocles, Fábio, Temístocles, Cipiāo, Sertório, Coriolano ou Tito.

Refere depois que o livro, cuja feitura sugere, ainda não existe em português e propóe-se mostrar como se faria, experimentando compor um capítulo que poderia ter como assunto a Justiça (1963: I 734735). Ora o paradigma a que recorre é o de Lúcio Júnio Bruto, um dos heróis de Roma que aparece em Plutarco, em especial na Vida de Publícola - ou melhor, o seu acto de aplicar a justiça, sem acepção de pessoas, mesmo aos próprios filhos, implicados numa conspiração que, à traição, planeara devolver a cidade de Roma à monrquia, entregando-a de novo ao governo dos Tarquínios. Descobertos, presos e processados por tal crime, os conspiradores compareceram ante Lúcio Júnio Bruto, cônsul nesse ano, que os interrogou inclusive os próprios filhos. Provado e confessado o crime, "pronuncia a fatal sentença: "O crime está provado; os acusados são réus de alta traição: lictores feri, executai a sentença da república”». Não vacilou na sentença o cônsul, mas o seu amor de pai não foi capaz de assistir à execução, cobrindo o rosto com a toga para não ver as cabeças dos filhos que rolaram a seus pés. Estive a citar, quase, as palavras de Garrett. E este seu exemplo pode ter subjacentes os capítulos 3-7 da Vida de Bublicola de Plutarco e o passo do Livro II de $A b$ Urbe Condita de Tito Lívio em que o episódio vem narrado (2. 3-5). Embora o texto do autor português

mais abaixo, como Marco Bruto, que os dois nomeia Garrett. 
não coincida exactamente com nenhum dos dois - em nenhum deles se encontra o pormenor de cobrir o rosto -, está contudo mais próximo do de Plutarco que, pelo menos, explicita que o cônsul Lúcio Júnio Bruto se retirou para não assistir à execução dos filhos (Publicola 6. 4-5).

Almeida Garrett termina a carta citando o Emílio de Rousseau que, subvalorizando a história e historiadores modernos, manifesta predilecção pelos antigos e entre estes dá como modelo preferível Plutarco (1963: I 739-740), com esta conclusão de Emílio: «o meu homem cá para mim, é Plutarco». Transcrevendo esta afirmação, Garrett póe-lhe alguma moderação, embora o autor das Vidas Paralelas continue a aparecer como paradigma a imitar:

E eu por mim creio que nem Plutarco que é só biógrafo da Antiguidade, nem um Plutarco moderno, em que se juntassem com os Varôes ilustres de então os dos tempos de agora, devia ser o primeiro livro do educando. Factos memoráveis soltos é que devem compor a primeira parte desta antologia moral; na segunda virão mui propriamente as vidas inteiras, mas resumidas, de homens célebres antigos e modernos: essa sim, essa deve ser um Plutarco da mocidade».

$\mathrm{Na}$ "Carta Sétima” (1963: I 741-747), às duas secçóes da antologia moral, sugeridas na carta anterior e especificadas no passo acima transcrito, acrescenta «uma terceira parte para a educaçáo do soberano» que "será um Plutarco de Príncipes, uma colecção de vidas de reis, 
de imperadores e de chefes de Estado» (1963 I: 743), paradigmas que aconselha a ir buscar à história ao longo dos tempos, mas sobretudo às figuras da Grécia e de Roma, cuja escolha já está praticamente feita em Plutarco (1963 I: 744):

Dessa rica e variada história da Grécia e Roma, dessa história por excelência, em que não há virtude nem vício do coração humano que não tenha seu exemplar, está quase toda feita a escolha nas Vidas de Plutarco.

Garrett acrescenta que com Plutarco e «com Cornélio Nepote será fácil» a tarefa do organizador dessa antologia, mas considera que há necessidade de correcçóes pontuais - cortar «onde é longo para a atenção de tão poucos anos», "lançar mais espesso véu onde o muito nu da pintura ofenderia olhos tão inocentes», "rectificar uma ou outra opinião fabulosa» -, porque, conclui, "Os Paralelos de Plutarco não são ainda para esta idade» (1963: I 744-745). A educação a que se refere é a do fim da puerícia e passagem para a adolescência, idade que Garrett coloca entre os sete e os catorze anos.

A “Carta oitava” (1963: I 748-754), ao procurar aplicar a um príncipe de Portugal os princípios anteriormente estabelecidos, refere que, ao objectivo de recolha de exemplos destinados à referida antologia, a "crónica de uma família» é preferível à «história de um povo» e que «o plano de Suetónio, de Tácito e de Plutarco» serve «melhor que o de Tucídides e Tito 
Lívio» (1963: I 748). Ou seja, Plutarco continua como o paradigma que Garrett aponta para ser seguido na feitura dessa espécie de Tesouro ou Espelho de Príncipes.

E o polígrafo de Queroneia volta a ser apresentado como modelo na "Carta décima" (1963 I: 762-768), que aborda a questão da educação física e da educação feminina. Recorrendo à opiniáo de Rousseau e de Madame Campan, reflecte sobre o exercício intelectual e as disciplinas aconselháveis a desenvolverem «a memória e o entendimento» (1963: I 766-767), considerando que uma e outro "quase se cultivam ao mesmo tempo e por meios simultâneos», se bem que a primeira mais temporã do que o segundo. É neste contexto que, em sua opiniáo, terminada a aprendizagem da leitura e da escrita, se deve começar «a fazer transcrever e decorar pelo nosso educando alguns trechos escolhidos, fáceis, simples dos melhores autores». Em nota elucida (1963: I 767 n.2) que esses exercícios devem ser praticados a partir da antologia já antes sugerida, "na suposição de termos um livro histórico, um Plutarco segundo o descrevi nas cartas antecedentes». E assim mais uma vez é Plutarco que ocorre de imediato ao pensamento de Garrett e a obra que tem em mente e elege como modelo são as Vidas Paralelas, náo o tratado De liberis educandis.

Em conclusão, várias vezes Almeida Garrett se declara devedor de Plutarco ou o erige como seu paradigma. Além de nomear e apresentar como modelos muitos dos biografados das Vidas do polígrafo 
de Queroneia, sem dizer explicitamente que essa é a sua fonte, confessa abertamente em outros passos que está a imitar Plutarco ou sugere que ele seja o modelo a seguir. Tal torna-se evidente em especial no opúsculo $D a$ Educação. No entanto, quando se esperaria que Almeida Garrett tivesse em mente neste opúsculo o De Liberis Educandis - o Da Ecucação das Crianças - as mençóes de Plutarco são feitas sobretudo com o pensamento nas Vidas Paralelas e nas figuras aí apresentadas, a que Garrett apelida genericamente 'os homens de Plutarco'. 